\title{
Utilização de Placas de polipropileno e fios de náilon na técnica de fixação espinhal segmentar modificada em uma jibóia
}

\author{
Polypropylene plates and nylon suture in a modified technique of segmental spinal fixation \\ in a redtail boa
}

\author{
Simone Borges Salgueiro De Simone ${ }^{I}$ Mariana Batista AndradeII Líria Queiroz Luz Hirano ${ }^{\text {III }}$ \\ Flávia Resende Martins Costa ${ }^{\text {III }}$ André Luiz Quagliatto Santos ${ }^{\text {IV }}$
}

\section{- NOTA -}

\section{RESUMO}

Um exemplar adulto de Boa constrictor com histórico de atropelamento foi atendido no Hospital Veterinário. Exames clínico e radiográfico identificaram a presença de uma luxação no terço médio da coluna vertebral. O paciente foi submetido à estabilização cirúrgica da lesão, em que se avaliou a eficácia de uma variação da técnica de fixação espinhal segmentar modificada. O segmento foi estabilizado através da fixação e placas plásticas sob forma de hemicerclagem nos corpos vertebrais, com auxílio de fio de náilon n. 0 e a síntese tecidual finalizou o procedimento. No pós-operatório, instituiu-se a antibioticoterapia, curativos locais diários e restrição de espaço até a cicatrização total do ferimento. A variação da técnica mostrou ser eficaz no realinhamento e estabilização anatômica da luxação do segmento vertebral para a serpente em questão.

Palavras-chave: Boa constrictor, Boidae, cirurgia, coluna vertebral, luxação.

\section{ABSTRACT}

An adult exemplar of Boa constrictor with a history of overthrowing was send to the Veterinary Hospital. Clinical and radiographic examinations identified the presence of a dislocation in the third middle of the spine. The patient was submitted to a surgical correction of the lesion, which evaluated the effectiveness of a variation of the modified technique of segmental spinal fixation. The segment was stabilized by fixing plastic plates in the form of hemicerclage in the vertebral bodies, with nylon n.0, and tissue synthesis completed the procedure. Postoperatively, it was instituted antibiotic therapy, daily

\begin{abstract}
curatives and space restrictions until the complete healing of the wound. The variation of the technique has proved to be safe and effective for the snake of this study, promoting the realignment and stabilization of the anatomical vertebral segment.
\end{abstract}

Key words: Boa constrictor, Boidae, hip dislocation, spine, surgical

A interferência antrópica no meio natural e migração da fauna para ambientes urbanizados contribuem para o aumento de traumatismos em animais silvestres (BASTOS et al., 2003). Grande parte das lesões em ofídeos acomete a coluna vertebral e a fixação espinhal é o tratamento cirúrgico de eleição para traumas que incluem déficit neurológico expressivo, elevado grau de compressão medular, fraturas instáveis ou estáveis, com pouca ou nenhuma resposta a terapia conservativa (LANNZ et al., 2000).

Devido à peculiar anatomia das serpentes $\mathrm{e}$ seus variados movimentos, há a necessidade da elaboração de novas técnicas cirúrgicas com o intuito de preservar a integridade anatômica da espécie. Tal conduta resulta na possibilidade de retorno do animal ao seu ambiente natural, garantindo seu bem estar (BROOM, 1986).

IPrograma de Pós-graduação em Ciências Veterinárias, Universidade Federal de Uberlândia (UFU), 38400-902, Uberlândia, MG, Brasil. E-mail: simonebssimone@ hotmail.com. Autor para correspondência.

IIMédica Veterinária Autônoma, Clínica Veterinária Pé de Cachorro, Uberlândia, MG, Brasil.

IIIPrograma de Pós-graduação em Ciência Animal, Universidade Federal de Goiás (UFG), Goiânia, GO, Brasil.

${ }^{\mathrm{IV}}$ Laboratório de Ensino e Pesquisa em Animais Silvestres, UFU, Uberlândia, MG, Brasil. 
Sendo assim, objetivou-se avaliar a eficácia da variação da técnica de fixação espinhal segmentar modificada, com o uso de placas de resina poliamida e fios de náilon, em coluna vertebral de jibóia (Boa constrictor).

Uma jibóia de vida livre, vítima de atropelamento foi encaminhada ao Hospital Veterinário e, durante seu exame físico, constatou-se crepitação no terço médio da coluna vertebral, associada à ausências de movimentação e sensibilidade caudalmente à lesão. Através de exames radiográficos, confirmou-se a luxação entre as vértebras 105 e 106, localizadas no terço médio da coluna do animal (Figura 1a) e a disposição do eixo da coluna revelou grande probabilidade de lesão medular, entretanto, não foram realizados exames específicos para a comprovação dessa suspeita.
O animal foi submetido à cirurgia de correção da coluna vertebral, através da técnica de fixação segmentar dorsal modificada. Realizou-se antibiótico profilaxia com cefazolina sódica, 30 minutos antes da cirurgia por via intramuscular (IM) profunda, na dose de $20 \mathrm{mg} \mathrm{kg}^{-1}$. Como protocolo anestésico, utilizou-se a associação cloridrato de tiletamina e cloridrato de zolazepan na dose de $25 \mathrm{mg} \mathrm{kg}^{-1} \mathrm{IM}$.

Após assepsia, procedeu-se à incisão de pele e fáscia muscular na linha mediana dorsal, estendendo-se por quatro vértebras craniais e quatro caudais ao local do trauma. A musculatura epiaxial foi rebatida lateralmente com auxilio de uma gaze, a fim de expor os processos espinhosos. Procedeu-se à correção por elevação e tração do corpo da serpente, que, ao retornar à posição anatômica, teve suas vértebras reposicionadas e alinhadas.

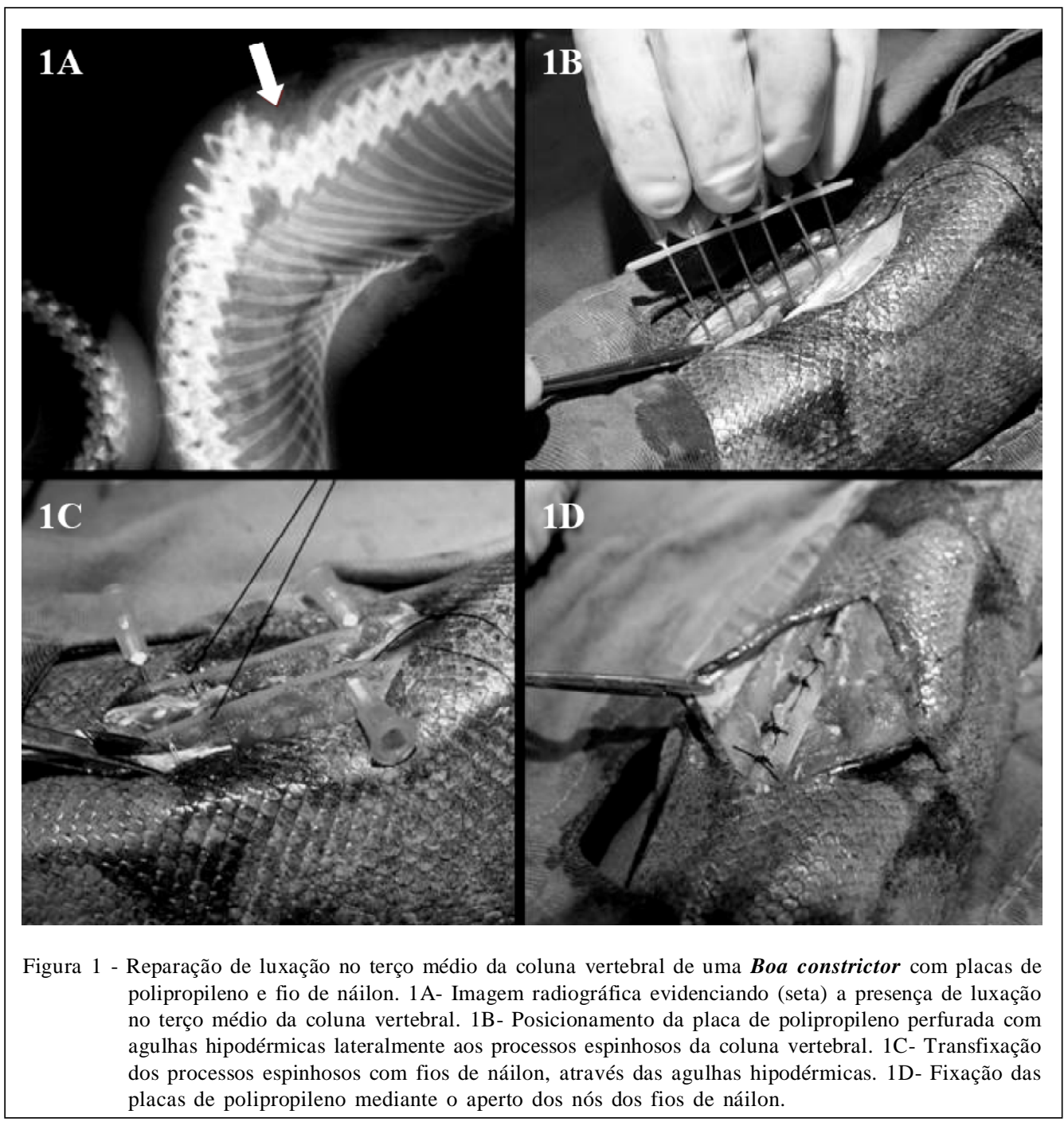

Ciência Rural, v.41, n.5, mai, 2011. 
Para a imobilização interna, duas placas de polipropileno $^{\text {a }}(230 \mathrm{~mm})$ perfuradas por agulhas hipodérmicas $(25 \times 8 \mathrm{~mm})$ foram posicionadas juntas à face lateral de dois processos espinhosos craniais e dois caudais à luxação (Figura 1b), os quais foram transpassados pelas agulhas e transfixados por fios de náilon n.0 (Figura 1c). Após tal manobra, as agulhas foram retiradas e procedeu-se ao aperto dos nós (Figura 1d).

A musculatura foi suturada com fio de mononáilon n.3-0 em padrão simples contínuo e a pele, coaptada com sutura wolf e fio de mononáilon n.3.0. No pós-operatório, utilizou-se cefazolina $\left(20 \mathrm{mg} \mathrm{kg}^{-1}\right.$, IM) a cada 24 horas por 15 dias e meloxicam $\left(0,3 \mathrm{mg} \mathrm{kg}^{-1}\right.$ IM) na mesma frequência diária, por cinco dias. Além disso, foram feitos curativos diários com iodopovidona e restringiu-se o espaço da serpente até a cicatrização total do ferimento.

Após a recuperação anestésica, a serpente demonstrou movimentações leves de cabeça e em 30 dias realizava tentativas de locomoção do corpo e movimentos de serpentear na porção cranial à lesão, entretanto, a parte caudal não apresentou sinais de sensibilidade ou movimento. Aos 45 dias posteriores à reparação cirúrgica, o animal foi encaminhado pelo IBAMA a um criatório conservacionista.

As imagens radiográficas revelaram luxação entre as vértebras 105 e 106, que, em conjunto com a instabilidade vertebral, diminuição de sensibilidade dolorosa e capacidade motora, evidenciaram a necessidade de alinhamento e estabilização do segmento vertebral através da correção cirúrgica em concordância com a literatura encontrada (ARIAS et al., 2007).

Técnicas de estabilização de coluna descritas em animais domésticos incluem métodos de imobilização interna com diferentes materiais (BRUECKER \& SEIM, 1993), como placas de PVC ou metálicas (DE YOUNG \& PROBST, 1993), parafusos ou pinos de Steinmann em formato de $\mathrm{U}$ fixados com fio de aço (GAGE, 1971) ou náilon (MC ANULTY et al., 1986) nos processos articulares ou espinhosos dorsais. Entretanto, essas técnicas não poderiam ser usadas em ofídeos, por serem materiais resistentes que obstariam a biomecânica natural de seus movimentos.

Diante as alternativas, a utilização de placas de polipropileno apresentou benefícios em relação à resistência aliada à flexibilidade do material. Em concordância com SMITH (1985), o qual relatou que biomateriais utilizados em cirurgias ortopédicas devem cumprir requisitos clínicos básicos, como possuir propriedades mecânicas para sua função de fixação e serem econômicos, em ordem decrescente de importância.
O uso da placa plástica de polivinilcarbonato no corpo vertebral é recomendado por YTURRASPE \& LUMB (1972) e WALKER et al. (1985), pois, apesar de rígidas e pouco flexíveis, são passíveis de ajustes ao comprimento e à curvatura vertebral (KELLEY et al., 1987). Tais benefícios contribuíram para a utilização de placas plásticas no referido espécime, no entanto, teriam que ser mais flexíveis que as de polivinilcarbonato, visando a manter os movimentos naturais do animal.

Na correção cirúrgica da coluna vertebral de Boa constrictor, optou-se pela imobilização de apenas dois processos espinhosos, cranial e caudal ao local de instabilidade, conforme sugestão de RENEGAR (1990), o que evitou o enrijecimento de um grande segmento espinhal. Entretanto, WALKER et al. (1985) e WALTER et al (1986) afirmaram que, frente às forças de flexão, o meio mais seguro de imobilizar a coluna vertebral seria através da fixação não só dos processos espinhosos como do corpo vertebral, porém a espessura do osso em questão não permitia tal feito.

A utilização de fios de mononáilon nesta técnica conferiu uma eficácia com vantagens comparáveis às da fixação segmentar dorsal modificada, pois foi capaz de promover uma reparação estável na região sem provocar fraturas de processos espinhosos e articulares durante a manobra de aperto do nó (PEDRO NETO et al., 2004), uma vez que o náilon apresenta filamentos de poliamida em sua composição que proporciona boa resistência tênsil e elasticidade (HENDLER, 2000).

A utilização de placas de resina poliamida e fios de náilon promoveram satisfatória estabilidade à luxação de coluna vertebral da $B$. constrictor desse relato e permitiu ao animal manter seus movimentos de serpentear cranialmente à lesão.

\section{FONTE DE AQUISIÇÃO}

a - Telacre, Sapucaia - RJ

\section{REFERÊNCIAS}

ARIAS, M.V.B. et al. Trauma medular em cães e gatos: revisão da fisiopatologia e do tratamento médico. Semina - Ciências agrárias, v.28, n.1, p.115-134, 2007. Disponível em: <http:/ /www.uel.br/revistas/uel/index.php/semagrarias/article/view/ 2568/2233>. Acesso em: 22 jul. 2010.

BASTOS, R.P. et al. Anfíbios da floresta nacional de Silvânia, estado de Goiás. Goiânia: RP Bastos, 2003. 82p.

BROOM, D.M. Indicators of poor welfare. British veterinary journal, v.142, p.524-526, 1986.

BRUECKER, K.A.; SEIM, H.B. Spinal fractures and luxations. In: SLATTER, D. Textbook of small animal surgery. 2.ed. Philadelphia: Saunders, 1993. p.1110-1121. 
DE YOUNG, D.J.; PROBST, C.W. Methods of internal fracture fixation. General principies. In: SLATTER, D. Textbook of small animal surgery. 2.ed. Philadelphia: Saunders, 1993. p.1610-1631.

GAGE, E.D. Surgical repair of spinal fractures in small breed dogs. Small Animal Clinician, v.66, n.11, p.1095-1101, 1971.

HENDLER, K. Basic principles of treatment: hard and soft tissue. In: FONSECA, R.J. Oral and maxillofacial surgery. Philadelphia: Saunders, 2000. p.25-44.

KELLEY, B.S. et al. Totally resorbable high-strength composite material. In: GEBELEIN, C.G. Advances in biomedical polymers. New York: Plennum, 1987. p.75-85.

LANNZ, O. et al. Initial assessment of patients with spinal cord trauma. Veterinary medicine, v.95, n.11, p.851-853, 2000.

MC ANULTY, J.F. et al. Modified segmental instrumentation in the repair of spinal fractures and luxations in dogs. Veterinary surgery, v.15, p.143-149, 1986. Disponível em: <http:// on linelibrary.wiley.com/doi/10.1111/j. 1532 950X.1986.tb00192.x/pdf>. Acesso em: 29 jun. 2010. doi: 10.1111/j.1532-950X.1986.tb00192.x.
PEDRO NETO, O. et al. Utilização de fios de náilon na técnica de fixação segmentar dorsal modificada. Clínica veterinária, v.49, p.43-50, 2004.

RENEGAR, W.R. Axial skeletal fractures. In: WHITTICK, W.G. Canine orthopedics. 2.ed. Philadelphia: Lea \& Febiger, 1990. p.308-356.

SMITH, G.K. Orthopaedic biomaterials. In: NEWTON, C.D.; NUNAMAKER, D.M. Textbook of small animals orthopaedics. Philadelphia: Lippincott, 1985. p.120-128.

YTURRASPE, J.; LUMB, W.V. The use of plastic plates for internal fixation of the canine spine. Journal of the American Veterinary Medical Association, v.161, p.1651-1657, 1972.

WALKER, T.L. et al. Disease of the spinal column. In: SLATTER, D.H. Textbook of small animal surgery. Philadelphia: Saunders, 1985. p.1367-1395.

WALTER, M.C. et al. Canine lumbar spinal internal fixation techniques. A comparative biomechanical study. Veterinary surgery, v.15, n.2, p.191-198, 1986. Disponível em: <http:/ /onlinelibrary.wiley.com/doi/10.1111/j.1532950X.1986.tb00203.x/pdf>. Acesso em: 15 jun. 2010. doi: 10.1111/j.1532-950X.1986.tb00203.x. 